\title{
An inhaled steroid improves markers of airway inflammation in patients with mild asthma
}

\author{
A. Jatakanon, S. Lim, K.F. Chung, P.J. Barnes
}

An inhaled steroid improves markers of airway inflammation in patients with mild asthma. A. Jatakanon, S. Lim. K.F. Chung, P.J. Barnes. OERS Journals Ltd 1998.

ABSTRACT: Airway inflammation can be demonstrated in mildly asthmatic patients who are not treated with inhaled steroids. Current guidelines recommend that inhaled steroids should be introduced in mild asthmatics who use an inhaled $\beta_{2}$-agonist more than once daily. It was postulated that inhaled steroids can have antiinflammatory effects in patients with even milder disease.

The effect of 4 weeks of treatment with budesonide $(800 \mu \mathrm{g}$ twice daily by Turbohaler®) was studied in 10 steroid-naïve mildly asthmatic patients (forced expiratory volume in one second $($ FEV1 $)=96 \pm 1.4 \%$ predicted $)$ who required an inhaled $\beta_{2}$-agonist less than one puff daily, in a double-blind, placebo-controlled, crossover fashion. Spirometry, exhaled nitric oxide (NO), bronchial responsiveness (provocative concentration causing a $20 \%$ fall in FEV1 (PC20)), and sputum induction were performed before and after each treatment period.

Following budesonide treatment, there were significant improvements in FEV1, and $\mathrm{PC20}$, in association with a significant reduction in the percentage of eosinophils in induced sputum. Exhaled NO levels tended towards reduction, but the change was nonsignificant. There were also nonsignificant reductions in sputum eosinophil cationic protein and tumour necrosis factor- $\alpha$ levels.

In conclusion inhaled budesonide can lead to improvements in noninvasive markers of airway inflammation, in association with a small improvement in lung function, even in mildly asthmatic patients who require an inhaled $\beta_{2}$-agonist less than once daily. This suggests a potential benefit of inhaled corticosteroids, even in relatively asymptomatic asthma.

Eur Respir J 1998; 12: 1084-1088.
Dept of Thoracic Medicine, National Heart and Lung Institute, Imperial College, London, UK.

Correspondence: P.J. Barnes

Dept of Thoracic Medicine

National Heart and Lung Institute

Dovehouse St

London SW3 6LY

UK

Fax: 441713515675

Keywords: Asthma

budesonide

eosinophil cationic protein

eosinophils

induced sputum

nitric oxide

Received: June 51997

Accepted after revision May 261998

Support by Astra Draco, Lund, Sweden. $\mathrm{AJ}$ was in receipt of a research fellowship from the Royal Thai Government, Thailand.
Airway inflammation is central to the pathophysiology of asthma [1] and anti-inflammatory drugs have become the mainstay of treatment in chronic asthma. Inhaled corticosteroids are the most potent anti-inflammatory drugs currently available and have now become the first-line therapy in patients with persistent asthma [2]. Early introduction of inhaled steroids is now recommended [3] as it may improve lung function [4] and prevent complications, such as irreversible airway damage or exacerbation [5]. However, few studies have compared the effect of inhaled steroids and placebo on airway inflammation in the same subjects, possibly owing to the lack of noninvasive methods that can be used repeatedly and effectively to evaluate the severity of airway inflammation.

Analysis of induced sputum has become an accepted method of assessing the inflammatory events that occur in asthmatic airways [6-8]. Different methods of sputum induction and processing have been developed, which are well tolerated and reproducible in terms of cellular and soluble markers of airway inflammation $[9,10]$. Increased numbers and activation of eosinophils in induced sputum are common findings in asthmatic patients, as compared with normal subjects $[6,7]$. The percentage of eosinophils in sputum is increased in asthmatics during exacerbations [11] or after allergen challenge [12]. In contrast, sputum eosinophil numbers are reduced after corticosteroid treatment, in association with an improvement in airway function and asthma symptoms $[13,14]$. There is also evidence to suggest that sputum eosinophilia or eosinophil cationic protein (ECP) levels in sputum can reflect the severity of airway inflammation $[15,16]$. Therefore, monitoring of eosinophil numbers in induced sputum could be a simple objective measure to reflect the severity of inflammation in asthma airways.

Exhaled nitric oxide (NO) levels are elevated in asthmatic patients untreated with inhaled steroids as compared with normal subjects [17]. The acute inflammatory response induced by allergen challenge in the airways is accompanied by elevated exhaled NO levels [18]. The levels are decreased following treatment with corticosteroids [19] but unchanged after treatment with a bronchodilator alone [20]. Recently, a relationship has been demonstrated between exhaled NO levels, sputum eosinophil numbers and airway hyperresponsiveness in asthmatic subjects not treated with inhaled steroids [21]. This suggests that monitoring of exhaled NO levels may also be useful as an indication of the inflammatory status of the airways.

The aim of this study was to evaluate the beneficial effect of corticosteroid treatment in subjects with mild asthma who required less than one puff of inhaled $\beta_{2}$-agonist 
daily by monitoring lung function and noninvasive markers of airway inflammation, such as sputum eosinophil numbers and exhaled NO. No previous studies have compared these parameters in the same patients in a doubleblind, placebo-controlled manner.

\section{Material and methods}

\section{Subjects}

Ten nonsmoking, stable, atopic, asthmatic patients (table 1 ) who only needed $\beta_{2}$-agonist therapy on demand were recruited into the study. Stable asthma was defined as having a prebronchodilator forced expiratory volume in one second (FEV 1 ) Š $80 \%$ predicted, no oral or inhaled steroid use, and no history of an exacerbation within the previous 12 months. All patients had a history of wheezing and chest tightness, were previously diagnosed by a physician as having asthma and had a provocative concentration of methacholine producing a $20 \%$ fall in $\mathrm{FEV}_{1}\left(\mathrm{PC}_{20}\right)$ ð4 $\mathrm{mg} \cdot \mathrm{mL}^{-1}$. The study protocol was approved by the Ethics Committee of the Royal Brompton Hospital.

\section{Study design}

The study was double-blind, randomized and crossover in design. Following the screening visit, patients were randomly allocated to receive either inhaled budesonide in a dry powder inhaler (Turbohaler®) $800 \mu \mathrm{g}$ b.i.d. (group 1) or matching placebo (group 2) for 4 weeks. The washout period was 4 weeks between treatment periods 1 and 2 . FEV1, exhaled NO, PC20 and sputum induction were measured consecutively before and after each treatment period. Patients recorded morning and evening peak flow rate (best of three) using a mini-Wright peak flow meter

Table 1. - Patients characteristics

\begin{tabular}{ccccccc}
\hline $\begin{array}{c}\text { Patient } \\
\text { No. }\end{array}$ & yge & Sex & $\begin{array}{c}\text { FEV1 } \\
\% \text { pred }\end{array}$ & $\begin{array}{l}\text { PC20 } \\
\mathrm{mg} \cdot \mathrm{mL}^{-1}\end{array}$ & DSS* $^{*}$ & $\begin{array}{c}\beta_{2} \text {-agonist } \\
\text { needed } \\
\text { puffs } \cdot \text { day }\end{array}$
\end{tabular}

Group 1 (Budesonide/Placebo)

$\begin{array}{cccrlll}1 & 24 & \mathrm{~F} & 120.3 & 0.88 & 1.1 & 0.9 \\ 2 & 31 & \mathrm{~F} & 86.7 & 2.69 & 1.1 & 0.4 \\ 3 & 28 & \mathrm{M} & 90.5 & 1.36 & 0 & 0 \\ 4 & 27 & \mathrm{~F} & 100.0 & 0.71 & 0 & 0 \\ 5 & 28 & \mathrm{~F} & 90.5 & 1.31 & 0.7 & 0 \\ \text { Mean } & 27.6 & & 97.6 & 1.24 \dagger & 0.6 & 0.3 \\ \text { SEM } & 1.1 & & 6.1 & 1.26^{\dagger} & 0.2 & 0.2\end{array}$

Group 2 (Placebo/Budesonide)

$\begin{array}{cccrlll}1 & 25 & \mathrm{M} & 116.3 & 0.53 & 0.1 & 0.3 \\ 2 & 29 & \mathrm{~F} & 83.5 & 0.06 & 0.9 & 0.9 \\ 3 & 36 & \mathrm{~F} & 98.2 & 1.0 & 1.9 & 0.9 \\ 4 & 26 & \mathrm{~F} & 96.1 & 1.16 & 0 & 0 \\ 5 & 29 & \mathrm{~F} & 80.0 & 0.18 & 0.6 & 0.8 \\ \text { Mean } & 29 & & 94.8 & 0.37 \dagger & 0.7 & 0.6 \\ \text { SEM } & 1.9 & & 6.4 & 1.75 & 0.3 & 0.2\end{array}$

*: mean daily symptom score (DSS) (minimum $=0$, maximum $=$ 9); ${ }^{\circ}$ geometric mean and geometric SEM. FEV1: forced expiratory volume in one second; $\mathrm{PC} 20$ : provocative concentration of methacholine causing a $20 \%$ fall in FEV1; F: female, M: male.
(Clement Clarke International, Essex, UK), symptom scores (asthma during the day, asthma during the night and early morning tightness, ranging 0 to 3 for each item) and the need for inhaled $\beta_{2}$-agonist daily on diary cards provided.

\section{Lung function}

FEV1 and forced vital capacity (FVC) were measured by dry spirometry (Vitalograph, Buckingham, UK). The best value of the three manoeuvres was expressed as a percentage of predicted value. Morning and evening peak expiratory flow (PEF) was measured using a mini-Wright peak flow meter.

\section{Bronchial responsiveness}

Bronchial responsiveness was measured by inhalation methacholine challenge, with a doubling concentration of methacholine $\left(0.06-32 \mathrm{mg} \cdot \mathrm{mL}^{-1}\right)$ delivered by dosimeter (Mefar, Bovezzo, Italy) [22]. The aerosols were inhaled at tidal breathing, wearing a noseclip. A total of five inhalations of each concentration were administered (inhalation time $1 \mathrm{~s}$, breath-holding time $6 \mathrm{~s}$ ). FEV1 was measured 2 min after the last inhalation, until there was a fall in FEV1 of Š20\% compared with the control inhalation $(0.9 \%$ saline solution) or until the maximal concentration was inhaled. The PC20 was calculated by interpolation of the logarithmic dose-response curve.

\section{Exhaled nitric oxide measurement}

End-exhaled NO was measured by a chemiluminescence analyser (Model LR2000; Logan Research, Rochester, UK) using a previously described method [23]. In brief, subjects exhaled slowly at a flow rate of 5-6 L. $\mathrm{min}^{-1}$ from total lung capacity (TLC) over 30-40 s through a mouthpiece. NO was sampled from a side-arm attached to the mouthpiece. The mean value was taken from the point corresponding to the plateau of the end-exhaled $\mathrm{CO}_{2}$ reading $\left(5-6 \% \mathrm{CO}_{2}\right)$ and representing the lower respiratory tract sample. Results of the analyses were computed and graphically displayed on a plot of $\mathrm{NO}$ and $\mathrm{CO}_{2}$ concentrations, pressure and flow against time.

\section{Sputum induction and processing}

Sputum induction was performed 15 min after patients recovered from the methacholine challenge test. Spirometry was recorded $15 \mathrm{~min}$ after $200 \mu \mathrm{g}$ of inhaled salbutamol via a metered-dose inhaler. Subjects were instructed to wash their mouth thoroughly with water. They then inhaled $3.5 \%$ saline at room temperature nebulized by an ultrasonic nebulizer (DeVilbiss Co., Heston, UK) at the maximum saline output $\left(4 \mathrm{~mL} \cdot \mathrm{min}^{-1}\right)$. Subjects were encouraged to cough deeply at three-minute intervals until the 15-minute induction time had been completed. Mouthwashing before each cough was encouraged in order to minimize salivary contamination. The initial sample from the first cough was discarded. Sputum was collected into a $50 \mathrm{~mL}$ polypropylene tube, kept at $4^{\circ} \mathrm{C}$, and processed within $2 \mathrm{~h}$. 
Spirometry was repeated after sputum induction. If there was a $15 \%$ drop in FEV1, the subject would be required to stay for observation until FEV1 had returned to the baseline.

For sputum processing, $2 \mathrm{~mL}$ Hank's balanced salt solution (HBSS) containing 1\% dithiothreitol (DTT) (Sigma Chemicals, Poole, UK) was added to the sputum. The mixture was vortexed and repeatedly aspirated at room temperature until the sputum was homogenized. Samples were left at room temperature for $5 \mathrm{~min}$. The sputum volume was then recorded, further diluted with HBSS up to 10 $\mathrm{mL}$, vortexed briefly and centrifuged at $400 \times g$ for $10 \mathrm{~min}$ at $4^{\circ} \mathrm{C}$. The final concentration of DTT in all specimens was $0.2 \%$.

Sputum supernatants were kept at $-70^{\circ} \mathrm{C}$ for subsequent cytokine assays. The cell pellets were resuspended. Total cell counts were performed on a haemacytometer using Kimura stain. An adequate sample was defined as having the number of squamous epithelial cells in fresh sputum specimen $<50 \%$ of the number of inflammatory cells. Slides were prepared using cytospin (Shandon, Runcorn, UK) and stained with May-Grünwald Giemsa for differential cell counts, which were performed by an observer blind to the clinical characteristics of the subjects. At least two slides were used for counting and at least 300 inflammatory cells were counted on each slide. The reproducibility of differential cell counts performed on 18 paired samples obtained from the same asthmatics within 1-2 weeks showed intraclass correlation coefficients of 0.75 for eosinophils, 0.78 for neutrophils, 0.76 for macrophages and 0.56 for lymphocytes.

\section{Eosinophil cationic protein assay}

All sputum supernatants were recentrifuged at $10,000 \times g$ for 5 min before the assay was performed. ECP concentrations were measured by radioimmunoassay (Pharmacia \& UpJohn Diagnostics, Uppsala, Sweden). The detection limit of the assay was $<2 \mathrm{mg} \cdot \mathrm{L}^{-1}$. Reproducibility of the assay, assessed from 18 paired samples collected within 1-2 weeks, showed an intraclass coefficient of 0.8 .

\section{Tumour necrosis factors- $\alpha$ assay}

Tumour necrosis factors- $\alpha$ (TNF- $\alpha$ ) in sputum supernatant was measured using an amplified sandwich enzymelinked immunosorbent assay (ELISA) by the technique described previously [8]. The detection limit of the assay was $<8 \mathrm{pg} \cdot \mathrm{mL}^{-1}$. Reproducibility of the assay, performed on 15 pairs of samples within an interval of $1-2$ weeks, showed an intraclass correlation coefficient of 0.8 .

\section{Data analysis}

Data are expressed as mean \pm SEM unless stated otherwise. PC20 were log transformed before analysis and ex-pressed as geometric mean values. ECP and TNF- $\alpha$ levels reported were corrected according to the dilutional factor and sputum volume. Firstly, the carryover effects of budesonide on the outcomes measured were determined according to standard recommended guidelines [24]. Only when this was not demonstrable, was the effect of budesonide treatment evaluated. The mean values of morning PEF, PEF variability (maximal amplitude \%), total symptom scores, and use of reliever inhaler (puffs.day ${ }^{-1}$ ) calculated from the last 7 days of each treatment period were used to evaluate the treatment effects. A two-sample t-test or an equivalent Mann-Whitney test was used for analysis. A pvalue of $<0.05$ was considered significant.

\section{Results}

All patients completed the study. The subjects' characteristics at baseline are summarized in table 1 . There were no significant differences in baseline airway function, PC20, asthma symptom scores or daily requirements for inhaled $\beta_{2}$-agonist between the two groups. Data on main outcomes such as FEV1, sputum eosinophils, exhaled NO and $\mathrm{PC}_{20}$ at baseline and after each treatment period are shown in table 2 .

Table 2. - Forced expiratory volume in one second (FEV1), sputum eosinophils, exhaled nitric oxide (NO) and provocative concentration of methacholine causing a $20 \%$ fall in FEV 1 (PC20) at baseline, following budesonide (Bud) and placebo treatments

\begin{tabular}{|c|c|c|c|c|c|c|c|c|c|c|c|c|c|c|c|c|}
\hline \multirow{2}{*}{$\begin{array}{l}\text { Patient } \\
\text { No. } \\
\end{array}$} & \multicolumn{4}{|c|}{$\mathrm{FEV}_{1} \mathrm{~L} \cdot \mathrm{min}^{-1}$} & \multicolumn{4}{|c|}{ Sputum eosinophils \% } & \multicolumn{4}{|c|}{ Exhaled NO ppb } & \multicolumn{4}{|c|}{ PC20 log transformed } \\
\hline & B1 & P1 & B2 & $\mathrm{P} 2$ & B1 & P1 & B2 & $\mathrm{P} 2$ & B1 & P1 & B2 & $\mathrm{P} 2$ & B1 & P1 & B2 & $\mathrm{P} 2$ \\
\hline \multicolumn{17}{|c|}{ Sequential group 1 (period (P1): budesonide treatment; period 2 (P2): placebo treatment) } \\
\hline 1 & 3.9 & 3.7 & 3.6 & 3.4 & 2.0 & 1.0 & 0.5 & 0 & 60 & 20 & 37 & 34 & -0.055 & 0.46 & -0.439 & -0.903 \\
\hline 2 & 3.0 & 3.0 & 3 & 2.8 & 0.5 & 0 & 0 & 0.2 & 21 & 5 & 21 & 23 & 0.43 & 0.87 & 0.301 & 0.602 \\
\hline 3 & 3 & 4.7 & 4.4 & 4.8 & 1.1 & 0.2 & 0.5 & 0 & 76 & 35 & 35 & 25 & 0.133 & 1.204 & -0.124 & 0.301 \\
\hline 4 & 3.1 & 3.3 & 3.1 & 3.2 & 2.3 & 0.3 & 2 & 1.7 & 18 & 10 & 16 & 15 & -0.148 & 0.9 & 0.9 & 0 \\
\hline 5 & 2.8 & 2.8 & 2.8 & 2.5 & 13 & 5 & 12 & 8 & 32 & 40 & 30 & 25 & 0.118 & 0.6 & -0.183 & -0.696 \\
\hline Mean & 3.28 & 3.46 & 3.38 & 3.34 & 3.8 & 1.3 & 3.0 & 2.0 & 41.4 & 22 & 27.8 & 24.4 & 0.095 & 0.806 & 0.091 & -0.139 \\
\hline \multicolumn{17}{|c|}{ Sequential group 2 (period (P1): placebo treatment; period (P2): budesonide treatment) } \\
\hline 1 & 5.0 & 5.0 & 4.3 & 5.2 & 3 & 7.3 & 8.2 & 0 & 55 & 53 & 65 & 19 & -0.275 & -0.6 & -1.22 & 0.517 \\
\hline 2 & & 3.2 & 3.1 & 3.3 & 12 & 9 & 16 & 6.8 & 90 & 65 & 65 & 17 & -1.22 & -0.9 & -1.22 & -0.3 \\
\hline 3 & 3. & 3.3 & 3.3 & 3.4 & 6.8 & 4.3 & 0.8 & 0.3 & 15 & 33 & 30 & 8 & 0 & -0.6 & -0.1 & 0.9 \\
\hline 4 & 3 & 3.2 & 3.2 & 3.4 & 0.4 & 2 & 0.5 & 0 & 16 & 11 & 18 & 12 & 0.064 & 0.114 & -0.602 & 0.467 \\
\hline 5 & 2.5 & 2.4 & 3.4 & 3.4 & 15.8 & 7 & 3.7 & 0.3 & 24 & 20 & 24 & 18 & -0.747 & -0.73 & -0.045 & -0.343 \\
\hline Mean & 3.54 & 3.42 & 3.46 & 3.74 & 5.5 & 3.3 & 4.0 & 2.1 & 40 & 36.4 & 40.4 & 14.8 & -0.435 & -0.543 & -0.677 & 0.248 \\
\hline
\end{tabular}

B1: baseline 1; B2: baseline 2; parts per billion. 


\section{Sputum characteristics}

As the effect of budesonide treatment on sputum ECP and TNF- $\alpha$ levels may be confounded by salivary contamination, comparisons between specimens collected after each treatment in terms of volume, total number and proportion of squamous cells were made. There were no significant differences in sputum volume $(2.7 \pm 0.5$ and $3.7 \pm 0.7 \mathrm{~mL})$, total number of squamous epithelial cells $(0.09 \pm 0.03$ and $\left.0.1 \pm 0.03 \times 10^{6} \cdot \mathrm{mL}^{-1}\right)$ or proportion of squamous epithelial cells $(18.0 \pm 3.2$ and $22.7 \pm 4 \%)$ between the samples collected after treatment.

Treatment with budesonide resulted in a significant reduction in sputum eosinophil number $(\mathrm{p}<0.005$, table 3 ). The proportion of eosinophils following budesonide and placebo treatments were $1.4 \pm 0.8$ and $4.0 \pm 1.1 \%$ respectively. There were no significant effects of budesonide on total cell count, macrophages (\%), neutrophils (\%) and lymphocytes (\%), ECP or TNF- $\alpha$ in induced sputum.

Compared with placebo, treatment with budesonide resulted in a significant increase in mean PC20 (table 3). The PC20 following budesonide and placebo treatment was $3.37 \pm 1.44$ and $0.53 \pm 1.48 \mathrm{mg} \cdot \mathrm{mL}^{-1}$, respectively $(\mathrm{p}<0.001)$. FEV1 and morning PEF (table 3) were also improved following budesonide $\left(3.6 \pm 0.2\right.$ and $474 \pm 35 \mathrm{~L} \cdot \mathrm{min}^{-1}$ respectively) compared with placebo $\left(3.4 \pm 0.3\right.$ and $\left.450 \pm 33 \mathrm{~L} \cdot \mathrm{min}^{-1}\right)$ $(\mathrm{p}<0.05)$. No significant changes in mean symptom scores, PEF variability or the use of rescue $\beta$-agonists were demonstrated (table 3 ). Exhaled NO levels were decreased following budesonide treatment $(18.4 \pm 3.6 \mathrm{ppb})$ compared with placebo $(30.4 \pm 5.3 \mathrm{ppb})$, but this failed to reach the level of significance $(\mathrm{p}=0.07$, table 3$)$.

\section{Discussion}

This double-blind, placebo-controlled, crossover study, evaluated the anti-inflammatory effect of an inhaled corticosteroid on noninvasive markers of airway inflammation and lung function in steroid-naïve asthmatic patients with normal lung function who required rescue, short-acting $\beta_{2}$-agonist less than one puff daily. The results indicate a potential benefit of corticosteroid treatment, as there was a reduction in sputum eosinophil numbers in association with an improvement in airway function and airway hyperresponsiveness. The associated reduction in exhaled NO level following budesonide treatment, even though not statistically significant $(\mathrm{p}=0.07)$, indicates that inhaled corticosteroids may have a suppressive effect on inducible nitric oxide synthase (iNOS) gene expression in airway epithelial and inflammatory cells [25]. The clinical utility of exhaled NO for monitoring asthma control, however, remains to be established, especially in subgroups of patients with more severe asthma.

Current asthma treatment guidelines propose restoring normal or best lung function and preventing both shortterm and long-term complications such as an exacerbation or irreversible airway damage [3]. Monitoring lung function, PEF variability, asthma symptoms and the amount of rescue $\beta_{2}$-agonist required daily is recommended to assess the control of asthma. In these patients with mild asthma, however, no significant changes in these parameters could be demonstrated, except for a small improvement in airway function. This implies that a small change in airway inflammation may not be effectively monitored by these conventional measures. Monitoring noninvasive markers of airway inflammation may provide additional information regarding the change in airway inflammation, especially in patients with very mild asthma. However, it is necessary to emphasize that the anti-inflammatory effects of inhaled steroids could be either dose or time dependent [26] and a high dose of inhaled steroids for 4 weeks was used in this study. With differing dosages and different treatment periods, each inflammatory marker may show different degrees of responsiveness to inhaled steroids. For example, a rather slow responsiveness of $\mathrm{PC}_{20}$ to inhaled steroids has been demonstrated previously [27]; therefore, it may not be useful as a marker of early response to low-dose inhaled steroids. Prospective studies to compare dose-responsiveness to inhaled steroids of sputum eosinophils, $\mathrm{PC} 20$, and exhaled $\mathrm{NO}$ are required to establish further their clinical utility.

The failure to demonstrate significant decreases in sputum measurements could be due to the very mild severity of asthma studied. This may affect the level of mediators in the sputum. Low levels of ECP and TNF- $\alpha$ were measured in the sputum of these patients, with little room for

Table 3. - Effects of budesonide on airway function, sputum eosinophils and inflammatory mediators, exhaled nitric oxide (NO), provocative concentration of methacholine causing a $20 \%$ fall in the forced expiratory volume in one second (PC20) and asthma symptoms

\begin{tabular}{|c|c|c|c|c|c|}
\hline & Group $1 *$ (Bud-Pla) & Group $2 *($ Pla-Bud $)$ & $\begin{array}{l}\text { Mean difference } \\
\text { groups } 1 \text { and } 2\end{array}$ & $\begin{array}{c}\text { Treatment effect } \\
\text { p-value }\end{array}$ & $\begin{array}{c}\text { Carryover effect } \\
\text { p-value }\end{array}$ \\
\hline $\mathrm{FEV} 1 \mathrm{~L} \cdot \mathrm{min}^{-1}$ & $0.2 \pm 0.0$ & $-0.4 \pm 0.2$ & $0.5 \pm 0.2(0.1-0.9)$ & $<0.05$ & NS \\
\hline $\mathrm{MMF} \mathrm{L} \cdot \mathrm{min}^{-1}$ & $26 \pm 11$ & $-23 \pm 16$ & $49 \pm 20(2-95)$ & $<0.05$ & NS \\
\hline Sputum eosinophils $\%$ & $-0.7 \pm 0.7$ & $4.4 \pm 1.1$ & $-5.1 \pm 1.3(-8.1-2.0)$ & $<0.005$ & NS \\
\hline $\mathrm{ECP} n g \cdot \mathrm{mL}^{-1}$ & $-139 \pm 316$ & $-49 \pm 50$ & $-90 \pm 320(-828-648)$ & NS & NS \\
\hline TNF- $\alpha$ pg.mL -1 & $-55 \pm 113$ & $-37 \pm 22$ & $-17.4 \pm 115(-329-295)$ & NS & NS \\
\hline Exhaled NO ppb & $-2.4 \pm 6.4$ & $21.6 \pm 9.3$ & $9.6 \pm 6.7(-50.2-2.2)$ & $=0.07$ & NS \\
\hline $\log \mathrm{PC}_{20}$ & $0.94 \pm 0.19$ & $-0.79 \pm 0.22$ & $1.73 \pm 0.29(1.1-2.4)$ & $<0.001$ & NS \\
\hline PEF variability $\%$ & $-1.8 \pm 3.5$ & $1.3 \pm 2.3$ & $-3.2(-12.9-6.5)$ & NS & NS \\
\hline Total symptom scores & $0.0 \pm 0.3$ & $0.0 \pm 0.6$ & $0.0(-1.5-1.4)$ & NS & NS \\
\hline Reliever inhaler puffs.day ${ }^{-1}$ & $-0.2 \pm 0.2$ & $0.1 \pm 0.9$ & $-0.4(-2.5-1.8)$ & NS & NS \\
\hline
\end{tabular}

Data are presented as mean \pm SEM (95\% confidence interval of mean). Group 1 received budesonide (Bud) treatment first, followed by placebo (Pla). Group 2 received placebo treatment first, followed by budesonide. *: The values measured at the end of first treatment period minus the same values measured at the end of the second treatment period (group 1: Budesonide - Placebo; group 2: Placebo Budesonide). MMF: mean morning peak expiratory flow: ECP eosinophil cationic protein; TNF- $\alpha$ : tumour necrosis factor- $\alpha$; PEF: peak expiratory flow; FEV1: forced expiratory volume in one second. 
improvement following corticosteroid treatment. There is evidence to suggest that ECP and cytokine levels in sputum reflect asthma severity $[16,28]$. In order to demonstrate a statistically significant reduction in sputum ECP, a wider range of asthma severity, including subjects with more severe asthma, may be needed, as demonstrated in a previous study [14]. This could also explain the lack of difference in TNF- $\alpha$ levels after budesonide and placebo treatments. In addition, there is evidence that TNF- $\alpha$ may not be sensitive to the anti-inflammatory effects of corticosteroids [14]. Another potential shortcoming of using the whole expectorate to monitor cytokine levels in induced sputum is dilution with saliva. The variable amounts of salivary contamination within the whole expectorate may also influence the outcome of sputum measurements. This was less likely to occur in the present study, as an attempt was made to minimize this by instructing patients to rinse their mouth before producing sputum. In addition, the volume of expectorate and number of squamous epithelial cells were compared within samples and there were no significant differences. These results, therefore, emphasize the significance of cellular monitoring but question the sensitivity of monitoring soluble mediator and cytokine concentration in induced sputum obtained from very mildly asthmatic patients.

In conclusion, even in relatively asymptomatic asthmatics, inhaled steroids can lead to improvements in noninvasive markers of airway inflammation, as well as a small improvement in lung function. This indicates a potential benefit of inhaled steroids in asymptomatic asthma. However, long-term studies are required to justify the clinical benefit of early steroid treatment in very mild asthma.

\begin{abstract}
Acknowledgements: The authors thank S. Ahlstedt (Pharmacia \& UpJohn Diagnostics, Uppsala, Sweden) for assistance with ECP reagents and P. Venge (University of Uppsala, Uppsala, Sweden) for ECP analysis.
\end{abstract}

\section{References}

1. Djukanovic R, Roche WR, Wilson JW, et al. Mucosal inflammation in asthma. Am Rev Respir Dis 1990; 142: 434-457.

2. Barnes PJ, Pedersen S. Efficacy and safety of inhaled corticosteroids in asthma. Am Rev Respir Dis 1993; 148: S1-26.

3. British Thoracic Society. The British Guidelines on Asthma Management. Thorax 1997; 52: S1-S21.

4. Haahtela T, Jarvinen M, Kava T, et al. Comparison of a beta-2-agonist, terbutaline, with an inhaled corticosteroid, budesonide, in newly detected asthma. $N$ Engl J Med 1991; 325: 388-392.

5. Haahtela T, Jarvinen M, Kava T, et al. Effects of reducing or discontinuing inhaled budesonide in patients with mild asthma. N Engl J Med 1994; 331: 700-705.

6. Pin I, Gibson PG, Kolendowicz R, et al. Use of induced sputum cell counts to investigate airway inflammation in asthma. Thorax 1992; 47: 25-29.

7. Fahy JV, Liu J, Wong H, Boushey HA. Cellular and biochemical analysis of induced sputum from asthmatic and from healthy subjects. Am Rev Respir Dis 1993; 147: 1126-1131.

8. Keatings VM, Collins PD, Scott DM, Barnes PJ. Differences in interleukin-8 and tumor necrosis factor-alpha in induced sputum from patients with chronic obstructive pulmonary disease or asthma. Am J Respir Crit Care Med 1996; 153: 530-534.
9. Pizzichini L, Pizzichini MM, Efthimiadis A, et al. Indices of airway inflammation in induced sputum: reproducibility and validity of cell and fluid-phase measurements. Am J Respir Crit Care Med 1996; 154: 308-317.

10. in't Veen JC, de Gouw HW, Smits HH, et al. Repeatability of cellular and soluble markers of inflammation in induced sputum from patients with asthma. Eur Respir $J$ 1996; 9: 2441-2447.

11. Gibson PG, Wong BJ, Hepperle MJ, et al. A research method to induce and examine a mild exacerbation of asthma by withdrawal of inhaled corticosteroid. Clin Exp Allergy 1992; 22: 525-532.

12. Pin I, Freitag AP, O'Byrne PM, et al. Changes in the cellular profile of induced sputum after allergen-induced asthmatic responses. Am Rev Respir Dis 1992; 145: 12651269.

13. Claman DM, Boushey HA, Liu J, Wong H, Fahy JV. Analysis of induced sputum to examine the effects of prednisone on airway inflammation in asthmatic subjects. J Allergy Clin Immunol 1994; 94: 861-869.

14. Keatings VM, Jatakanon A, Worsdell YM, Barnes PJ. Effects of inhaled and oral glucocorticoids on inflammatory indices in asthma and COPD. Am J Respir Crit Care Med 1997; 155: 542-548.

15. Alfaro C, Sharma OP, Navarro L, Glovsky MM. Inverse correlation of expiratory lung flows and sputum eosinophils in status asthmaticus. Ann Allergy 1989; 63: 251-254.

16. Virchow JC Jr, Holscher U, Virchow C Sr. Sputum ECP levels correlate with parameters of airflow obstruction. Am Rev Respir Dis 1992; 146: 604-606.

17. Kharitonov SA, Yates D, Robbins RA, Logan Sinclair R, Shinebourne EA, Barnes PJ. Increased nitric oxide in exhaled air of asthmatic patients. Lancet 1994; 343: 133-135.

18. Kharitonov SA, O'Connor BJ, Evans DJ, Barnes PJ. Allergen-induced late asthmatic reactions are associated with elevation of exhaled nitric oxide. Am J Respir Crit Care Med 1995; 151: 1894-1899.

19. Kharitonov SA, Yates DH, Barnes PJ. Inhaled glucocorticoids decrease nitric oxide in exhaled air of asthmatic patients. Am J Respir Crit Care Med 1996; 153: 454-457.

20. Yates DH, Kharitonov SA, Barnes PJ. Effect of short- and long-acting inhaled $\beta_{2}$-agonists on exhaled nitric oxide in asthmatic patients. Eur Respir J 1997; 10: 1483-1488.

21. Jatakanon A, Lim S, Kharitonov SA, Chung KF, Barnes PJ. Correlation between exhaled nitric oxide, sputum eosinophils, and methacholine responsiveness in patients with mild asthma. Thorax 1998; 53: 91-95.

22. Chai H, Farr RS, Frochlich LA, et al. Standardization of bronchial inhalation challenge procedures. J Allergy Clin Immunol 1975; 56: 323-327.

23. Kharitonov SA, Chung KF, Evans R, O'Connor BJ, Barnes PJ. Increased exhaled nitric oxide in asthma is mainly derived from the lower respiratory tract. Am J Respir Crit Care Med 1996; 153: 1773-1780.

24. Everitt BS. Statistical Methods in Medical Investigations $2^{\text {nd }}$ Edn. London, Edward Arnold, 1994; pp.78-91.

25. Springall DR, Meng Q, Redington A, Howarth PH, Evans TJ, Polak JM. Inducible nitric oxide syntase in asthmatic airway epithelium is reduced by corticosteroid therapy. Am J Respir Crit Care Med 1995; 151: A833.

26. Kraan J, Koeter GH, van der Mark TW, et al. Dosage and time effects of inhaled budesonide on bronchial hyperreactivity. Am Rev Respir Dis 1988; 137: 44-48.

27. Barnes PJ. Effect of corticosteroids on airway hyperresponsiveness. Am Rev Respir Dis 1997; 141: S70-S76.

28. Konno S, Gonokami Y, Kurokawa M, et al. Cytokine concentrations in sputum of asthmatic patients. Int Arch All-ergy Immunol 1996; 109: 73-78. 